\title{
Algumas notas sobre a dimensão ecológica da dignidade da pessoa humana e sobre a dignidade da vida em geral
}

Ingo Wolfgang Sarlet*

Tiago Fensterseifer**

Resumo: O presente estudo, à luz da teoria dos direitos fundamentais e da ordem jurídico-constitucional brasileira, analisa a dimensão ecológica da dignidade humana, bem como o reconhecimento da dignidade inerente a outras formas de vida não-humanas e à vida em geral.

\footnotetext{
"Doutor em Direito pela Universidade de Munique. Pós-Doutorado nas Universidades de Munique, Georgetown e Instituto Max-Planck de Direito Social Estrangeiro e Internacional (Munique). Coordenador do Programa de Pós-Graduação em Direito da PUC/RS. Professor do Doutorado em Direitos Humanos e Desenvolvimento da Universidade Pablo de Olavide (Sevilha). Juiz de Direito de Entrância Final (RS).

** Mestre em Direito Público pela PUCRS. Defensor Público no Estado de São Paulo. Organizador, juntamente com os Professores Ingo Wolfgang Sarlet, Carlos A. Molinaro e Fernanda Medeiros, de "A dignidade da vida e os direitos fundamentais para além dos humanos: uma discussão necessária”.
} 
Abstract: This study, in according of the theory of fundamental rights and brazilian legal system, examines the ecological dimension of human dignity and the recognition of the inherent dignity of non-human animals.

Sumário: 1. A dimensão ecológica da dignidade humana; 2. Dignidade da vida para além da humana?; 2.1. Sobre a necessidade de repensar a concepção kantiana individualista e antropocêntrica de dignidade e avançar rumo a uma compreensão ecológica da dignidade da pessoa humana e da vida em geral; 3 . A superação do paradigma jurídico antropocêntrico clássico e o reconhecimento da dignidade do animal não-humano e da vida em geral no âmbito jurídico-constitucional brasileiro; 4. Algumas questões em aberto - um novo contrato político-jurídico socioambiental?

\section{A DIMENSÃO ECOLÓGICA DA DIGNIDADE (DA PESSOA) HUMANA}

É do conhecimento de todos que a matriz filosófica moderna da concepção de dignidade humana tem sido reconduzida essencialmente e na maior parte das vezes ao pensamento do filósofo alemão IMMANUEL KANT. Especialmente no campo do Direito até hoje a fórmula elaborada por KANT informa a grande maioria das conceituações jurídico-constitucionais da dignidade da pessoa humana. ${ }^{1}$ A formulação kantiana coloca a idéia de que o ser humano não pode ser empregado como simples meio (ou seja, objeto) para a satisfação de qualquer vontade alheia, mas sempre deve ser tomado como fim em si mesmo (ou seja, sujeito) em qualquer relação ${ }^{2}$, seja em face do Estado seja em face de particulares. Isso se deve, em grande medida, ao reconhecimento de um valor intrínseco a cada existência humana, já que a fórmula de se tomar sempre o ser humano como um fim em si mesmo está diretamente vinculada às idéias de autonomia, de liberdade, de racionalidade e de autodeterminação inerentes à condição humana. A proteção ética e jurídica do ser humano contra qualquer "objetificação"

\footnotetext{
${ }^{1}$ Nesse sentido, cfr. o art. I da Declaração Universal dos Direitos Humanos (1948): "Todas as pessoas nascem livres e iguais em dignidade e direitos. São dotadas de razão e consciência e devem agir em relação umas às outras com espírito de fraternidade".

${ }^{2}$ KANT, Immanuel. Crítica da razão pura e outros textos filosóficos. Coleção Os Pensadores. Tradução de Paulo Quintela. São Paulo: Abril Cultural, 1974, p. 229.
} 
da sua existência e o respeito à sua condição de sujeito nas relações sociais e intersubjetivas são seguramente manifestações da concepção kantiana de dignidade da pessoa humana, embora, por certo, encontradas já em pensadores anteriores.

Sem que se vá - ainda - questionar alguns aspectos da concepção kantiana e voltando-nos ao direito constitucional positivo, há como partir da premissa de que a Constituição brasileira de 1988, no seu art. $1^{\circ}$, inciso III, consagra expressamente a dignidade da pessoa humana como o princípio fundamental (como fundamento do próprio Estado democrático de Direito), portanto, como ponto de partida e fonte de legitimação de todo o sistema jurídico pátrio. A dignidade da pessoa humana, como, aliás, já tem sido largamente difundido, assume a condição de matriz axiológica do ordenamento jurídico, visto que é a partir deste valor e princípio que todos os demais princípios (assim como as regras) se projetam e recebem os impulsos para os seus respectivos conteúdos normativo-axiológicos, o que não implica aceitação da tese de que a dignidade é o único valor a cumprir tal função e nem a adesão ao pensamento de que todos os direitos fundamentais (especialmente se assim considerados os que foram como tais consagrados pela Constituição) encontram seu fundamento direto e exclusivo na dignidade da pessoa humana ${ }^{3}$. Assim, a dignidade humana, para além de ser também um valor, configura-se como sendo juntamente com o respeito e a proteção da vida! - o princípio de maior hierarquia da nossa Constituição e de todas as demais ordens jurídicas que a reconheceram ${ }^{4}$. A dignidade da pessoa humana apresenta-se, além disso, como a pedra basilar da edificação constitucional do Estado (social, democrático e ambiental) de Direito brasileiro, na medida em que, sob a influência das luzes lançadas por KANT, o constituinte reconheceu que é o Estado que existe em função da pessoa humana, e não o contrário, já que o ser humano constitui a finalidade precípua, e

\footnotetext{
${ }^{3}$ Sobre este tópico v. SARLET, Ingo Wolfgang. Dignidade da Pessoa Humana e Direitos Fundamentais na Constituição Federal de 1988. 5.ed. Porto Alegre: Livraria do Advogado Editora, 2007, p. 81 e ss.

${ }^{4}$ SARLET, “Dignidade da pessoa humana...", p. 85.
} 
não meio da atividade estatal ${ }^{5}$, o que, diga-se de passagem, demarca a equiparação de forças na relação Estado-cidadão, em vista da proteção e afirmação existencial desse último, especialmente no que tange aos seus direitos fundamentais.

No âmbito de um Estado Socioambiental de Direito, tal qual consagrado na Constituição de 1988, pelo menos como se sugere no presente estudo ${ }^{6}$, a dignidade da pessoa humana é tomada como o principal, mas não o exclusivo fundamento (e tarefa) da comunidade estatal ${ }^{7}$, projetando a sua luz sobre todo o ordenamento jurídico-normativo e assim vinculando de forma direta todos os atores estatais e privados. Para além de uma força normativa autônoma como princípio (e também valor) jurídico a dignidade da pessoa humana se projeta especialmente em conjunto com toda uma gama de direitos tanto de natureza defensiva (negativa) como prestacional (positiva), implicando também toda uma gama de deveres fundamentais, que, embora não sejam necessariamente todos deduzidos diretamente da dignidade da pessoa humana, geralmente também atuam como concretizações em maior ou menor medida desta dignidade e que também por esta razão podem ser igualmente (como o princípio da dignidade individualmente considerado) opostos tanto em face do Estado quanto frente a particulares $^{8}$. Com isso, desde logo se afirma a necessidade de reconhecimento da eficácia dos direitos fundamentais (e principalmente da dignidade humana) também nas relações entre particulares, assim como o reconhecimento da dimensão normativa (vinculante) do princípio constitucional da solidariedade e dos deveres que lhe são inerentes.

\footnotetext{
${ }^{5}$ SARLET, "Dignidade da pessoa humana...", p. 68.

${ }^{6}$ Dentre outros fundamentos aptos a justificar a defesa de um Estado Socioambiental, verifica-se que há todo um percurso social, econômico, político, cultural e jurídico não concluído pelo Estado Social, ao qual se agrega hoje a proteção ambiental.

${ }^{7}$ HÄBERLE, Peter. "A dignidade humana como fundamento da comunidade estatal". In: SARLET, Ingo Wolfgang (Org). Dimensões da Dignidade: ensaios de Filosofia do Direito e Direito Constitucional. Porto Alegre: Livraria do Advogado, 2005, p. 116.

${ }^{8}$ Quanto ao desenvolvimento teórico da dignidade como limite e tarefa do Estado, da comunidade e dos particulares, vide o tópico 4.4 da obra de SARLET, Ingo Wolfgang. "Dignidade da pessoa humana...", especialmente, pp. 112-121.
} 
Em suma, o que se afirma é que a partir do princípio constitucional da dignidade humana, projeta-se todo um leque de posições jurídicas subjetivas e objetivas, com a função precípua de tutelar a condição existencial humana contra quaisquer violações do seu âmbito de proteção, assegurando o livre e pleno desenvolvimento da personalidade de cada ser humano.

Ainda nesse contexto, é possível destacar uma dimensão social (ou comunitária) da dignidade da pessoa humana, já que a dignidade, apesar de ser sempre em primeira linha a dignidade da pessoa concreta, individualmente considerada, necessariamente implica um permanente olhar para o outro, visto que indivíduo e a comunidade são elementos integrantes de uma mesma (e única) realidade político-social-estatal. Em outras palavras, a dignidade do indivíduo nunca é a do individuo isolado ou socialmente irresponsável, projetando-se na dignidade de todos os integrantes do grupo social. Como acentua CÁRMEN LÚCIA ANTUNES ROCHA, à luz de uma perspectiva fundada no princípio constitucional da solidariedade, "a dignidade humana - mais que aquela garantida à pessoa - é a que se exerce com o outro" " ${ }^{9}$ com o que apenas se enfatiza a perspectiva relacional da pessoa humana em face do corpo social que integra, bem como o compromisso jurídico (e não apenas moral) do Estado e dos particulares na composição de um quadro social de dignidade para (e com) todos.

Com efeito, não nos parece possível excluir de uma compreensão necessariamente multidimensional e não-reducionista da dignidade da pessoa humana, aquilo que se poderá designar de uma dimensão ecológica (ou, quem sabe, socioambiental) da dignidade humana, que, por sua vez, também não poderá ser restringida a uma dimensão puramente biológica ou física, pois contempla a qualidade de vida como um todo, inclusive do ambiente em que a vida humana (mas também a nãohumana) se desenvolve. É importante, aliás, conferir um destaque especial para as interações entre a dimensão natural ou biológica da

\footnotetext{
${ }^{9}$ ROCHA, Cármen Lúcia Antunes. "Vida Digna: Direitos, Ética e Ciência”. In: ROCHA, Cármen Lúcia Antunes (Coord.). O Direito à Vida Digna. Belo Horizonte: Editora Fórum, 2004, p. 78.
} 
dignidade humana e a sua dimensão ecológica (ou ambiental), que objetiva ampliar o conteúdo da dignidade da pessoa humana no sentido de um padrão de qualidade e segurança ambiental mais amplo (e não apenas no sentido da garantia da existência ou sobrevivência biológica), mesmo que muitas vezes esteja em causa a própria existência natural da espécie humana, para além mesmo da garantia de um nível de vida com qualidade ambiental.

Há uma lógica evolutiva nas dimensões da dignidade humana que também podem ser compreendidas a partir de uma perspectiva histórica da evolução dos direitos humanos e fundamentais, já que esses, em larga medida, simbolizam a própria materialização da dignidade humana em cada etapa histórica. Assim como outrora os direitos liberais e os direitos sociais formatavam o conteúdo da dignidade humana, hoje também os direitos de solidariedade, como é o caso especialmente da qualidade ambiental, passam a conformar o conteúdo da dignidade humana, ampliando o seu âmbito de proteção. Daí falarse em uma nova dimensão ecológica para a dignidade humana, em vista especialmente dos novos desafios existenciais de índole ambiental a que está submetida a existência humana neste mundo "de riscos" contemporâneo.

Como ponto de partida das reflexões subseqüentes, adotar-se-á o conceito jurídico de dignidade da pessoa humana formulado pelo primeiro autor deste ensaio ${ }^{10}$ como moldura conceitual-normativa aberta a uma reformulação parcial, especialmente para o efeito de enfatizar a inclusão de uma dimensão ecológica e, de tal modo, tornar o conceito mais responsivo aos novos (e velhos) desafios existenciais impostos pela degradação ambiental, mas também em vista da evolução cultural e dos novos valores

\footnotetext{
${ }^{10}$ Tem-se por dignidade humana "a qualidade intrínseca e distintiva reconhecida em cada ser humano que o faz merecedor do mesmo respeito e consideração por parte do Estado e da comunidade, implicando, neste sentido, um complexo de direitos e deveres fundamentais que assegurem a pessoa tanto contra todo e qualquer ato de cunho degradante e desumano, como venham a lhe garantir as condições existenciais mínimas para uma vida saudável, além de propiciar e promover sua participação ativa e coresponsável nos destinos da própria existência e da vida em comunhão com os demais seres humanos". SARLET, "Dignidade da pessoa humana...", p. 62.
} 
socioambientais legitimados no âmbito comunitário. Da mesma forma, a reflexão se propõe não apenas a extrapolar a dimensão humana, apontando para a necessidade de reconhecimento de uma dignidade da vida em geral, como também propõe o questionamento a respeito da possibilidade (e mesmo necessidade) de atribuição de dignidade às gerações humanas futuras e mesmo a outras formas de vida. Assim, para cumprir o nosso desiderato, propõe-se o seguinte percurso: após traçar uma moldura conceitual para a dignidade da pessoa humana à luz de uma matriz kantianoantropocêntrica, é que os seus limites conceituais e normativos serão ampliados em vista de uma comunicação do conceito com os novos valores culturais e éticos que sedimentam as relações socioambientais no marco da sociedade de risco ${ }^{11}$ (e em risco de extinção) no início de século XXI, bem como diante de sua necessária contextualização no âmbito de um modelo de Estado Socioambiental de Direito. Em razão de ser a dignidade humana a pedra fundamental de toda a edificação jurídico-constitucional contemporânea, qualquer modificação conceitual acaba por repercutir e projetar-se para todo o sistema jurídico, principalmente no que tange aos direitos fundamentais e a própria conformação do Estado de Direito. De outra parte, não é demais lembrar que o nosso propósito aqui é apenas de lançar algumas questões para o debate e de algum modo contribuir para o seu desenvolvimento, mesmo porque não é a certeza que nos move, mas a inquietude! A única certeza é a de que é preciso refletir e avançar.

\section{DIGNIDADE DA VIDA PARA ALÉM DA HUMANA?}

2.1. SOBRE A NECESSIDADE DE REPENSAR A CONCEPÇÃO INDIVIDUALISTA E ANTROPOCÊNTRICA DE DIGNIDADE E AVANÇAR RUMO A UIMA COMPREENSÃO ECOLÓGICA DA DIGNIDADE DA PESSOA HUMANA E DA VIDA EM GERAL

${ }^{11}$ BECK, Ulrich. La sociedad del riesgo: hacia una nueva modernidad. Barcelona: Paidós, 2001. 
Considerando aqui a premissa de que a matriz filosófica moderna para a concepção de dignidade (da pessoa humana) radica essencialmente no pensamento kantiano, qualquer tentativa de superação de tal "paradigma" teórico requer um diálogo com as suas formulações e argumentos. Embora não se possa aprofundar a discussão, enfatiza-se que a formulação central do pensamento kantiano, tal qual apontado acima, coloca a idéia de que o ser humano não pode ser empregado como simples meio (ou seja, objeto) para a satisfação de qualquer vontade alheia, mas sempre deve ser tomado como fim em si mesmo (ou seja, sujeito) em qualquer relação, seja em face do Estado seja em face de outros indivíduos $^{12}$. Com tal entendimento, está-se a atribuir um valor intrínseco a cada existência humana, demarcando o respeito à sua condição de sujeito nas relações sociais e intersubjetivas. Desde logo, verifica-se que é certamente possível questionar o excessivo antropocentrismo que informa tanto o pensamento kantiano ${ }^{13}$ quanto a tradição filosófica ocidental de um modo geral, especialmente confrontando-a com os novos valores ecológicos que alimentam as relações sociais contemporâneas e que reclamam uma nova concepção ética, ou, o que talvez seja mais correto, a redescoberta de uma ética de respeito à vida que já era sustentada por alguns. Assim, para ficarmos num exemplo, importa ter presente que a vedação de qualquer prática de "objetificação" (ou tratamento como simples “meio") não deve, em princípio, ser limitada apenas à vida humana, mas ter o seu espectro ampliado para contemplar também outras formas de vida. A fim de ampliar a concepção kantiana para além do ser humano, pretende-se, no presente trabalho, aderir aos que levantam o questionamento acerca

\footnotetext{
${ }^{12}$ KANT, “Crítica da razão pura...”, p. 229.

${ }^{13}$ A citação que segue marca de forma expressa o excessivo antropocentrismo no pensamento kantiano, sobre o qual se pretende refletir e verificar neste trabalho a sua pertinência e atualidade à luz dos novos valores ecológicos que permeiam o pensamento contemporâneo. "Os seres cuja existência depende, não em verdade da nossa vontade, mas da natureza, têm contudo, se são seres irracionais, apenas um valor relativo como meios e por isso se chamam coisas, ao passo que os seres racionais se chamam pessoas, porque a sua natureza os distingue já como fins em si mesmos, quer dizer, como algo que não pode ser empregado como simples meio e que, por conseguinte, limita nessa medida todo o arbítrio (e é um objeto do respeito).” KANT, “Crítica da razão pura...”, p. 229.
} 
da possibilidade de reconhecimento de um fim em si mesmo inerente a outras formas de vida (ou à vida de um modo geral), atribuindo-lhes um valor intrínseco, ou seja, uma dignidade, que igualmente implica um conjunto de deveres para o Homem e, se é possível questionar a existência de autênticos direitos, pelo menos de interesses fundamentais juridicamente tuteláveis, não sendo nosso propósito enunciar aqui juízos conclusivos a respeito de tal aspecto da problemática.

Todas as concepções (e a de Kant é apenas a mais influente!) que sustentam ser a dignidade atributo exclusivo da pessoa humana encontram-se, pelo menos em princípio, sujeitas à crítica de um excessivo antropocentrismo, notadamente naquilo em que sustentam que a pessoa humana, em função de sua racionalidade, ocupa lugar privilegiado em relação aos demais seres vivos. Para além disso, sempre haverá como sustentar a dignidade da própria vida de um modo geral, ainda mais numa época em que o reconhecimento da proteção do ambiente como valor fundamental indicia que não mais está em causa apenas a vida humana, mas a preservação de todos os recursos naturais, incluindo todas as formas de vida existentes no planeta, ainda que se possa argumentar que tal proteção da vida em geral constitua, em última análise, exigência da vida humana e vida humana com dignidade. ${ }^{14}$

Outra contribuição filosófica importante que modelou, em grande medida, o pensamento moderno de matriz iluminista, e que influencia até hoje o nosso método de abordagem científica (e o Direito não fica alheio a tal condicionamento), é a idéia de "animal-máquina" formulada por RENÉ DESCARTES (Discurso do Método, Quinta Parte). ${ }^{15}$ O filósofo francês defende a idéia de que os animais podem ser equiparados a máquinas móveis ou autômatos, já que, diferentemente do homem que é composto de corpo e alma (e, portanto, nunca poderia ser identificado com uma simples máquina), apenas possuem corpo. ${ }^{16}$ Ao afirmar que os animais não possuem nenhuma razão ${ }^{17} \mathrm{e}$, portanto, tampouco valor intrínseco, DESCARTES abriu caminho para a separação entre ser

\footnotetext{
${ }^{14}$ Tais reflexões encontram-se em SARLET, "Dignidade da pessoa humana...”, pp. 34-35. ${ }^{15}$ DESCARTES, René. Discurso do método; Meditações; Objeções e respostas; As paixões da alma; Cartas. Tradução de J. Guinsburg e Bento Prado Júnior. 2 ed. São Paulo: Abril Cultural, 1979, p. 60.
} 
humano e Natureza que até hoje marca a abordagem científica em quase todas as áreas do conhecimento, bem como para o processo de instrumentalização e apropriação da Natureza e dos recursos naturais, o que, em grande medida, tem nos conduzido ao atual estágio preocupante de degradação ambiental.

A "denúncia" feita acima pelo primeiro autor a respeito de um excessivo antropocentrismo em torno das concepções tradicionais de dignidade da pessoa humana é tomada como ponto de partida para a reflexão que se pretende levar adiante a partir de agora. Em que pese uma fundamentação doutrinária ainda frágil (pelo menos no campo jurídico) em defesa de uma perspectiva biocêntrica ou ecocêntrica para a concepção da dignidade humana (e também do Direito de um modo geral), a relevância do tema, diante da exposição existencial a que está submetido o ser humano contemporâneo e da emergência de novos valores culturais (veiculados, por exemplo, pelo movimento ecológico e pelo movimento dos direitos dos animais), parece justificar a presente tentativa de repensar a questão. De fato, o dilema existencial com que se defronta a humanidade hoje revela a fragilidade (para não dizer falácia) da separação cartesiana entre ser humano e Natureza. Em tempos de gripe aviária, vaca louca, poluição química, aquecimento global e outras questões que desnudam o vínculo existencial elementar existente entre ser humano e ambiente, revela-se como insustentável pensar o humano sem relacioná-lo diretamente com o seu espaço ambiental e toda a cadeia de vida que fundamenta a sua existência. Em vista disso, com a fragilização das bases naturais que lhe dão suporte, também a vida humana é colocada em situação vulnerável. Nesse contexto, assim como se fala em dignidade da pessoa humana, atribuindo-se valor intrínseco à vida humana, também parece possível conceber a dignidade da vida em geral, conferindo-se à Natureza ou às bases naturais da vida um valor intrínseco. Nessa perspectiva, o filósofo alemão HANS JONAS, em sua obra $O$ princípio da vida, à luz de uma biologia filosófica, busca reformular a compreensão ética moderna da

\footnotetext{
${ }^{16}$ DESCARTES, "Discurso do método...", p. 55.

${ }^{17}$ DESCARTES, "Discurso do método...", p. 61.
} 
relação entre ser humano e Natureza, em vista de afirmar que há algo de transcendente e espiritual já na própria base da vida (e não apenas na etapa evolutiva onde se encontra o ser humano), havendo, portanto, um valor intrínseco a ser reconhecido à própria existência orgânica como tal ${ }^{18}$.

Há importantes documentos legislativos internacionais e de direito comparado que abordaram a temática do valor intrínseco de formas de vida não-humanas. A Convenção sobre a Diversidade Biológica (1992) destaca, no início do seu preâmbulo, o reconhecimento do "valor intrínseco da diversidade biológica e dos valores ecológico, genético, social, econômico, científico, educacional, cultural, recreativo e estético da diversidade biológica e de seus componentes". Mais especificamente sobre a questão dos animais não-humanos, a Declaração Universal dos Direitos dos Animais da UNESCO $^{19}$ prevê o direito dos animais de existirem em um ambiente biologicamente equilibrado $\left(\operatorname{art} . \mathrm{I}^{\circ}\right)$, bem como que todos os animais têm o direito de ser respeitados $\left(\operatorname{art} .2^{\circ}\right)$. A idéia de respeito está diretamente vinculada ao reconhecimento de um valor intrínseco a determinada manifestação existencial, como ocorrido em relação aos seres humanos ao longo da nossa evolução cultural precedente, como, de resto, já destacado. $\mathrm{O}$ art. $4^{\circ}$ estabelece o direito dos animais silvestres de viverem livres no seu meio natural, sendo inadmissível qualquer uso de animais selvagens que não tenha uma razão vital ou existencial para o ser humano (questões meramente patrimoniais não poderiam fundamentar tais medidas). $\mathrm{O}$ art. $5^{\circ}$ destaca o direito ao bem-estar dos animais dependentes do ser humano (domésticos ou domesticados), fazendo referência, inclusive, ao respeito à sua dignidade. Não obstante a ausência de força jurídica da Declaração Universal dos Direitos dos Animais, a discussão moral nela

\footnotetext{
${ }^{18}$ JONAS, Hans. O princípio da vida. Tradução de Carlos Almeida Pereira. Petrópolis: Editora Vozes, 2004, p. 15.

${ }^{19}$ Destaca-se que o texto foi originalmente proclamado em 1978, sendo, posteriormente, em 1989, revisada pela Liga Internacional dos Direitos dos Animais, e tornado público na sua nova versão pelo Diretor-Geral da UNESCO em 1990. Disponível em: http:// league-animal-rights.org/en-duda.html. Acesso em: 03 de julho de 2006.
} 
consubstanciada teve ressonância no âmbito de vários ordenamentos jurídicos nacionais, que ao longo, principalmente, das últimas décadas, têm pautado a questão da proteção dos animais nas discussões políticas e jurídicas.

Nessa perspectiva, importa frisar a inovação incorporada pela Constituição Suíça ao reconhecer, em 1992, uma "dignidade da criatura" (Art. 24), que deve ser respeitada especialmente no âmbito da legislação sobre engenharia genética. O idealizador do "movimento" suíço de reforma constitucional, PETER SALADIN, sustenta um novo perfil constitucional para o tratamento da questão ambiental baseado em três princípios éticos: a) princípio da solidariedade (justiça intrageracional); b) princípio do respeito humano pelo ambiente não-humano (justiça interespécies); c) princípio da responsabilidade para com as futuras gerações (justiça intergeracional). ${ }^{20}$ Tal idéia traduz uma concepção de justiça ecológica, enfatizando o respeito e os deveres que o ser humano deve observar quando da sua interação com o meio natural.

No âmbito da Lei Fundamental da Alemanha, KLAUS BOSSELMANN refere que a introdução da expressão "bases naturais da vida", ao invés de "vida humana", marcou, com a inclusão do art. 20a na reforma constitucional de 1994, um passo para além de um antropocentrismo puro. No entanto, o debate prosseguiu no cenário jurídico e político alemão, especialmente por força do movimento em favor dos direitos dos animais, que seguiu pressionando para a inclusão da proteção dos animais como objetivo do Estado, o que veio a ocorrer em 2002, com o acréscimo da expressão “e os animais" (die Tiere) no art. 20a da Lei Fundamental. ${ }^{21}$ Por fim, refere o jurista alemão, atualmente radicado na Nova Zelândia, que, independentemente de a alteração constitucional ter ou não conduzido a interpretação do seu texto em favor de uma abordagem não-antropocêntrica, ficou registrado que o discurso ético marcou sua presença no âmbito do discurso

\footnotetext{
${ }^{20}$ SALADIN, Peter. Die Würde der Kreatur, Schriftenreihe Umwelt Nr. 260 (1994), S. 121. Apud BOSSELMANN, Klaus. "Human rights and the environment: the search for common ground”. In: Revista de Direito Ambiental, n. 23, jul-set, 2001, p. 41.

21 "Art. 20a (Fundamentos naturais da vida). No âmbito da ordem constitucional, o Estado protege as bases naturais da vida e os animais, tendo em conta também a sua
} 
jurídico. ${ }^{22}$ Nessa mesma perspectiva, verifica-se também a crescente importância das discussões provocadas pela corrente filosófica da ética animal, que, aos poucos, tem conseguido sensibilizar as estruturas jurídicas e, ainda que em parte e de modo incipiente, influir na remodelação do Direito em sintonia com um patamar mais evoluído das relações morais.

BOSSELMANN trabalha também com a idéia de direitos humanos (e fundamentais) ecológicos, os quais objetivam reconciliar a base filosófica dos direitos humanos com os princípios ecológicos, conectando o valor intrínseco do ser humano com o valor intrínseco de outras espécies e do ambiente como um todo. A partir de tal compreensão, os direitos humanos e fundamentais (como, por exemplo, a dignidade da pessoa humana, a liberdade, a propriedade e o desenvolvimento) precisam corresponder ao fato de que o indivíduo não opera somente num ambiente social, mas também num ambiente natural, o que, por sua vez - e o registro é nosso - igualmente guarda conexão com a compreensão do Estado Democrático de Direito como sendo sempre também um Estado Socioambiental. De acordo com a percepção de BOSSELMANN, assim como o indivíduo deve respeitar o valor intrínseco dos demais seres humanos, o indivíduo também deve respeitar o valor intrínseco de outros seres, como animais, plantas, ecossistemas, etc. ${ }^{23}$, fundamentando a existência de deveres (fundamentais) ecológicos do ser humano para com as demais manifestações existenciais. Nesse contexto, o jurista alemão afirma a importância dos direitos humanos e fundamentais para o enfrentamento dos desafios ecológicos, propondo a sua releitura diante dos novos princípios de natureza ecológica que passam a integrar as relações sociais (e também naturais) na sociedade contemporânea.

responsabilidade para com as futuras gerações, por meio do poder legislativo, e segundo a lei e o Direito por meio dos poderes executivo e judicial". (Tradução livre dos autores) 22 BOSSELMANN, Klaus. "Environmental Rights and Duties: the concept of ecological human rights". Artigo apresentado no $10^{\circ}$ Congresso Internacional de Direito Ambiental, em São Paulo, 5-8 de junho de 2006, p. 18, no prelo.

${ }^{23}$ BOSSELMANN, op. cit., p. 12. 
Direcionando fortes críticas ao tratamento dispensado aos animais pela filosofia kantiana, que os destituía de qualquer valor intrínseco e colocava os deveres dos seres humanos para com os animais apenas como um dever indireto para com a própria humanidade (justamente a perspectiva antropocêntrica ora questionada), MARTHA NUSSBAUM alerta para o fato de que o reconhecimento da dignidade de determinadas existências não-humanos implica uma questão básica de justiça, já que, na esteira do que foi afirmado por ARISTÓTELES, há algo de admirável ou respeitável (wonderful; wonder-inspiring) em todas as formas complexas de vida animal ${ }^{24}$. A autora, de outra parte, rejeita a idéia de compaixão e humanidade no tratamento dos animais não-humanos, defendendo uma idéia de justiça que transcenda tal perspectiva para reconhecer o valor intrínseco e a dignidade de animais não-humanos. A idéia de dever moral de um tratamento não-cruel dos animais deve buscar o seu fundamento não mais na dignidade humana ou na compaixão humana, mas sim na própria dignidade inerente às existências dos animais nãohumanos. Tal reflexão pode ser ampliada para a vida em termos gerais, não se limitando à esfera animal.

A inquestionável consagração da proteção ambiental no âmbito jusfundamental e o reconhecimento da qualidade de vida como elemento integrante da dignidade da pessoa humana acarretam a necessidade até mesmo de uma reformulação conceitual da dignidade da própria pessoa humana, de tal sorte que esta venha a guardar sintonia com os novos valores ecológicos. Com base em tais considerações, os desenvolvimentos em torno da natureza relacional e comunicativa da dignidade da pessoa humana contribuem para a superação de uma concepção eminentemente especista (biológica) e, portanto, necessariamente reducionista e vulnerável - de peculiar e específica dignidade dos seres humanos (que por si só, não afasta uma possível consideração da dignidade da vida de um modo geral). ${ }^{25}$ A atribuição

\footnotetext{
${ }^{24}$ NUSSBAUM, Martha C. "Beyond 'Compassion and Humanity': Justice for Nonhuman Animals”. In: SUNSTEIN, Cass R.; NUSSBAUM, Martha C. (Orgs.). Animal Rights: Current Debates and New Directions. Nova York: Oxford University Press, 2004, p. 306.
} 
de "dignidade" a outras formas de vida ou à vida em termos gerais transporta a idéia de respeito e responsabilidade que deve pautar o comportamento do ser humano para com tais manifestações existenciais. Nesse contexto, para além de uma compreensão "especista" da dignidade, que parece cada vez mais frágil diante do quadro existencial contemporâneo e dos novos valores culturais de natureza ecológica, deve-se avançar nas construções morais e jurídicas no sentido de ampliar o espectro de incidência do valor dignidade para outras formas de vida e da vida em si.

\section{A SUPERAÇÃO DO PARADIGMA JURÍDICO ANTROPOCÊNTRICO CLÁSSICO E O RECONHECIMENTO DA DIGNIDADE DO ANIMAL NÃO-HUMANO E DA VIDA EM GERAL NO ÂMBITO JURÍDICO- CONSTITUCIONAL BRASILEIRO}

No âmbito jurídico, principalmente por parte de autores que trabalham com o Direito Ambiental (ou Direito do Ambiente), tem sido suscitada alguma reflexão sobre a superação do paradigma antropocêntrico na regulação das relações jurídico-ambientais. ${ }^{26}$ Nessa linha, JOSÉ RUBENS MORATO LEITE, alinhado com a doutrina de CUNHAL SENDIN ${ }^{27}$, trabalha com o conceito do antropocentrismo alargado (ou moderado), objetivando a tutela do ambiente independentemente da sua utilidade direta ou benefícios ao homem,

\footnotetext{
${ }^{25}$ SARLET, "Dignidade da pessoa humana...", p. 57.

${ }^{26}$ FIGUEIREDO DIAS colaciona que uma das principais novidades postas pela abordagem jurídica do ambiente diz respeito justamente ao trânsito de uma concepção exclusivamente antropocêntrica do Direito para a afirmação de um princípio "biocêntrico" ou "ecocêntrico". DIAS, José Eduardo Figueiredo. Direito constitucional e administrativo do ambiente. Cadernos do Centro de Estudos de Direito do Ordenamento, do Urbanismo e do Ambiente. Coimbra: Almedina, 2002, p. 13.

${ }^{27}$ CUNHAL SENDIN, José de Souza. Responsabilidade Civil por Danos Ecológicos: da reparação do dano através de restauração natural. Coimbra: Coimbra Editora, 1998, pp. 98-104.
} 
ao considerar a preservação da capacidade funcional do patrimônio natural com ideais éticos de colaboração e interação homem-natureza. ${ }^{28}$ Nesta mesma perspectiva, indispensável a referência ao entendimento sustentado por ANTÔNIO HERMAN BENJAMIN, ao referir que a Constituição brasileira registrou a preservação e restauração de “processos ecológicos essenciais (art. 225, § $1^{\circ}$, I), e que, portanto, tal formulação constitucional transportaria a idéia de tais processos tutelados no âmbito constitucional seriam aqueles os essenciais à sobrevivência do planeta, concepção que ultrapassaria a fórmula tradicional da sobrevivência do apenas do homem. Assim, bem destaca o autor que "a tutela ambiental gradual e erraticamente abandona a rigidez de suas origens antropocêntricas e acolhe uma visão mais ampla, de caráter biocêntrico (ou mesmo ecocêntrico), ao propor-se a amparar a totalidade da vida e das suas bases" ${ }^{29}$.

Em sentido similar, VASCO PEREIRA DA SILVA defende o conceito de "antropocentrismo ecológico", o qual rejeita qualquer visão meramente instrumental, economicista ou utilitária da natureza, considerando que o ambiente deva ser tutelado pelo Direito, ao passo que a sua preservação é condição para a realização da dignidade da pessoa humana. ${ }^{30}$ Assim, em que pese a manutenção de uma compreensão antropocêntrica do Direito, na medida em que se propõe a sua moderação ou alargamento, tem-se já uma nova ótica para a compreensão da relação ser humano-Natureza, uma vez que ao meio natural está-se a atribuir um valor intrínseco, ou seja, está-se a reconhecer a Natureza, para usar a formulação kantiana, como um fim em si mesmo, apesar de esta dimensão ser relacional em face do ser

\footnotetext{
${ }^{28}$ LEITE, José Rubens Morato. Dano ambiental: do individual ao coletivo extrapatrimonial. São Paulo: Revista dos Tribunais, 2000, p. 79.

${ }^{29}$ Cf. BENJAMIN, Antônio Herman. "Constitucionalização do Ambiente e Ecologização da Constituição Brasileira”. In: CANOTILHO, José Joaquim Gomes; MORATO LEITE, José Rubens (Orgs.). Direito Constitucional Ambiental Brasileiro. São Paulo: Saraiva, 2007, p. 90.

${ }^{30}$ PEREIRA DA SILVA, Vasco. Verde Cor de Direito: lições de Direito do Ambiente. Coimbra: Almedina, 2002, pp. 29-30.
} 
humano, e não totalmente autônoma, como há de ser no contexto de um Estado Socioambiental de Direito.

A discussão sobre a atribuição de direitos à natureza em geral ou aos animais em especial tem suscitado discussões importantes na doutrina. Merece destaque, nesta perspectiva, a referência "clássica", inspirada em KANT, e ratificada por ASIS ROIG, a respeito dos deveres dos seres humanos em face dos animais, embora a existência, na base de tais deveres de tutela, unicamente um interesse humano ou da humanidade. Fazendo coro com tal premissa, ASIS ROIG sustenta que não é possível a atribuição de direitos aos animais, senão aos homens, de tal sorte que no caso dos deveres para com os animais, verifica-se um direito que tem sua origem em um interesse humano ou na idéia de solidariedade. Por fim, o autor espanhol equipara a tutela dos animais à tutela do patrimônio histórico e cultural, por dizerem respeito apenas a um interesse humano na sua proteção ${ }^{31}$. PEREIRA DA SILVA, também no intuito de negar a possibilidade de atribuição de direitos subjetivos à Natureza ou mesmo aos animais, acentua que "o Direito é um fenômeno da cultura, que regula relações entre seres livres e responsáveis que, por isso mesmo, devem ter consciência dos seus deveres de preservação do meio-ambiente" ${ }^{\text {"32 }}$, razão pela qual os direitos subjetivos seriam atribuíveis somente às pessoas, cabendo ao ambiente ou à Natureza apenas uma tutela de dimensão objetiva, muito embora o autor - e é preciso frisar este ponto - não defenda uma visão que se poderia designar de meramente instrumental da tutela dos animais e da vida não-humana.

Mesmo que se possa aceitar, pelo menos para efeitos de argumentação, a noção de que não há como atribuir típicos direitos aos animais ou à natureza, isto não afasta a necessidade (ética e jurídica) de se perguntar se essa tutela do meio natural não pode se dar de forma autônoma, com o reconhecimento de uma dignidade à vida não-humana e aos animais. Se a dignidade consiste em um valor próprio e distintivo

\footnotetext{
${ }^{31}$ ROIG, Rafael de Assis. Deberes y derechos en la Constitución. Madrid: Centro de Estudios Constitucionales, 1991, p. 172.

32 PEREIRA DA SILVA, “Verde Cor de Direito...", p. 31.
} 
que nós atribuímos à determinada manifestação existencial - no caso da dignidade da pessoa humana, a nós mesmos - é possível o reconhecimento do valor "dignidade" como inerente a outras formas de vida não-humanas. A própria vida, de um modo geral, guarda consigo o elemento dignidade, ainda mais quando a dependência existencial entre espécies naturais é cada vez mais reiterada no âmbito científico, consagrando o que FRITJOF CAPRA denominou de "teia da vida" FREITAS DO AMARAL posiciona-se no sentido de que, quando se está a legislar contra a crueldade frente aos animais, em verdade não se está a proteger a "delicadeza dos sentimentos do ser humano face aos animais", mas sim o animal em si mesmo, atribuindo-lhe um valor intrínseco. O ambiente não pode ser protegido apenas em razão da saúde e da qualidade de vida do ser humano, mas também em virtude de representar um valor em si mesmo. A partir de tais reflexões, o autor português, sem posicionar-se, lança também o questionamento se tais constatações implicam o reconhecimento de direitos dos animais (que, por vezes, também poderiam ser opostos aos seres humano) ${ }^{34}$.

No contexto de uma perspectiva histórico-cultural do Direito, vale trazer à colação o pensamento de BOBBIO quando, ao refletir sobre a trajetória histórica dos direitos humanos, marcando a passagem dos direitos de liberdade para os direitos políticos e sociais, lembra que ocorreu um deslocamento do foco centrado no indivíduo (uti singulus), na condição de primeiro sujeito ao qual foram atribuídos direitos naturais (ou morais), para sujeitos diferentes do indivíduo como, por exemplo, as minorias étnicas e religiosas, e também, mais recentemente, a humanidade considerada em seu conjunto, o que se dá em razão da necessidade de considerar os direitos das gerações humanas futuras. $\mathrm{O}$ jurista italiano ressalta, ainda, que o reconhecimento de direitos pode ser concebido para além de indivíduos humanos considerados singularmente ou comunitariamente, ou seja, para sujeitos diferentes

\footnotetext{
${ }^{33}$ CAPRA, Fritjof. A teia da vida: uma nova compreensão científica dos sistemas vivos. São Paulo: Cultrix, 1996.

${ }^{34}$ AMARAL, Diogo Freitas do. "Acesso à justiça em matéria de ambiente e de consumo". In: Textos “Ambiente e Consumo", Volume I. Lisboa: Centro de Estudos Jurídicos, 1996, p. 162.
} 
do ser humano, como os animais. Tais "direitos da natureza", impulsionados pelos movimentos ecológicos, postulam as mesmas palavras ("respeito" e "não-exploração") utilizadas tradicionalmente na definição e justificação dos direitos humanos ${ }^{35}$.

Seguindo-se a mesma linha argumentativa, é possível afirmar que a tendência contemporânea no sentido de uma proteção constitucional e legal da fauna e flora, bem como dos demais recursos naturais, inclusive contra atos de crueldade praticados pelo ser humano, revela no mínimo que a própria comunidade humana vislumbra em determinadas condutas (inclusive praticadas em relação a outros seres vivos) um conteúdo de indignidade. Tendo em conta que nem todas as medidas de proteção da natureza não humana têm por objeto assegurar aos seres humanos sua vida com dignidade (por conta de um ambiente saudável e equilibrado), mas dizem com a preservação, por si só, da vida em geral e do patrimônio ambiental, resulta evidente que se está a reconhecer um valor em si, isto é, intrínseco ${ }^{36}$.

A Constituição Federal brasileira, no seu art. 225, § 1 ${ }^{\circ}$, VII, enuncia de forma expressa a vedação de práticas que "provoquem a extinção de espécies ou submetam os animais à crueldade”, o que sinaliza o reconhecimento, por parte do constituinte, do valor inerente a outras formas de vida não-humanas, protegendo-as, inclusive, contra a ação humana $^{37}$, o que revela que não se está buscando proteger (ao menos diretamente e em todos os casos) apenas o ser humano. É difícil de conceber que o constituinte, ao proteger a vida de espécies naturais em face da sua ameaça de extinção, estivesse a promover unicamente a proteção de algum valor instrumental de espécies naturais; pelo contrário, deixou transparecer

\footnotetext{
${ }^{35}$ BOBBIO, Norberto. A era dos direitos. 10.ed. Tradução de Carlos Nelson Coutinho. Rio de Janeiro: Campus, 1992, p. 69.

${ }^{36}$ SARLET, "Dignidade da pessoa humana...", p. 35.

${ }^{37}$ Registra-se o descompasso entre a Lei de Proteção da Fauna (Lei 5.197/67) e a Constituição Federal, em razão do referido diploma legal, sob uma matriz eminentemente instrumental e patrimonialista da vida animal, restringir-se a determinar que a fauna silvestre é de propriedade do Estado, sem esboçar uma maior preocupação com o bemestar dos animais e a vedação de práticas cruéis, proibindo apenas alguns meios de abate de animais silvestres (especialmente no inciso "a" do art. 10).
} 
uma tutela da vida em geral nitidamente não meramente instrumental em relação ao ser humano, mas numa perspectiva concorrente e interdependente. Especialmente no que diz com a vedação de práticas cruéis contra os animais, o constituinte revela de forma clara a sua preocupação com o bem-estar dos animais não-humanos e a refutação de uma visão meramente instrumental da vida animal. A Constituição também traz de forma expressa no mesmo dispositivo a tutela da função ecológica da flora e da fauna, o que dá a dimensão de sistema ou ecossistema ambiental, no sentido de contemplar a proteção integrada dos recursos naturais (e aí incluído o ser humano). Dessa forma, está a ordem constitucional reconhecendo a vida animal como um fim em si mesmo, de modo a superar o antropocentrismo kantiano.

Como aludido acima, outro argumento importante para sustentar a dignidade da vida de um modo geral como um valor próprio (autônomo) é a proteção constitucional de espécies ameaçadas de extinção, porquanto, na maioria dos casos, a existência de determinada espécie no ambiente não traz nenhum benefício existencial direto (nem mesmo econômico) para o ser humano, igualmente contrariando a visão posta pela corrente antropocêntrico-instrumental dos recursos naturais. Com efeito, a proteção das espécies ameaçadas de extinção não representa a funcionalizacão (pelo menos não a mera funcionalização) da vida animal em razão da sua utilidade para o Homem, mas diz com uma dimensão objetiva de proteção, reconhecendo, de certa forma, um valor - que, também por implicar em deveres jurídicos de tutela e promoção, poderia muito bem ser denominado de "dignidade" - inerente àquela existência em risco de extinção. Deve-se destacar que a proteção de espécies ameaçadas de extinção é mais abrangente do que a vedação de práticas cruéis contra os animais, pelo fato de tutelar também a flora e todas as demais formas de vida que estiverem sujeitas à extinção, o que acaba por revelar, de certo modo, o reconhecimento, por parte do constituinte, de um valor inerente à vida de um modo geral como sendo digno e exigente de tutela.

No âmbito do ordenamento jurídico infraconstitucional, é oportuno voltar o olhar sobre o Direito Penal, no âmbito do qual se destaca a criminalização de condutas humanas que resultem em 
crueldade e maus-tratos contra animais. ${ }^{38}$ Subjacente a tal postura do legislador infraconstitucional, ainda mais quanto relida à luz do dever constitucional de proteção da fauna, ${ }^{39}$ está implícito o reconhecimento, ou melhor, a atribuição de um "valor", portanto, de uma dignidade, também a outras formas de vida além da humanas A Lei dos Crimes Ambientais (Lei 9.605/98), na Seção dos Crimes contra a Fauna, ao mesmo tempo em que criminaliza a conduta humana que atenta contra a vida e o bem-estar animal e caracteriza a reprovação social de tal prática, reconhece, em certa medida, um valor (dignidade?) inerente à vida animal, tutelando-a de forma autônoma e independentemente da sua utilidade ao ser humano. ${ }^{40}$

No $\S 1^{\circ}$ do art. 32, o tipo penal do caput é ampliado para abarcar também quem "realiza experiência dolorosa ou cruel em animal vivo, ainda que para fins didáticos ou científicos, quando existirem recursos alternativos", o que evidencia a adoção de um critério de proporcionalidade (designadamente o subcritério da necessidade) para justificar a utilização de animais em experiências científicas ou didáticas, ou seja, aquela prática só será juridicamente legítima quando não houver outros meios alternativos (menos lesivos) para realizar a experiência. Deve-se destacar que também a ponderação dos bens em conflito (tutela da fauna e benefícios científicos à saúde extraídos dos experimentos) deve ser procedida, a fim de contemplar

\footnotetext{
${ }^{38}$ A Lei dos Crimes Ambientais (Lei 9.605/98) também visa dar uma proteção especial às espécies raras ou ameaçadas de extinção, quando prevê de forma expressa um aumento de pena $\left(\S 4^{\circ}, \mathrm{I}\right)$ para o tipo penal do art. 29 quando este for impetrado em face de espécies naturais em tal condição de risco.

39 “Art. 225 (...) § $1^{\circ}$ Para assegurar a efetividade desse direito, incumbe ao Poder Público: (...) VII - proteger a fauna e a flora, vedadas, na forma da lei, as práticas que coloquem em risco na sua função ecológica, provoquem a extinção de espécies ou submetam os animais à crueldade".

${ }^{40}$ Art. 32. Praticar ato de abuso, maus-tratos, ferir ou mutilar animais silvestres, domésticos ou domesticados, nativos ou exóticos: Pena - detenção, de 3 (três) meses a $\mathrm{I}$ (um) ano, e multa; $\S 1^{\circ}$ Incorre nas mesmas penas quem realiza experiência dolorosa ou cruel em animal vivo, ainda que para fins didáticos ou científicos, quando existirem recursos alternativos; $\S 2^{\circ}$ A pena é aumentada de $1 / 6$ (um sexto) a 1/3 (um terço), se ocorre morte do animal. (grifos do autor)
} 
a proporcionalidade "em sentido estrito" e a constitucionalidade da medida, sempre em face de um caso concreto.

Seguindo essa linha de entendimento, valemo-nos das lições de SPORLEDER DE SOUZA, que, rompendo com a visão liberalindividualista (também antropocêntrica) do Direito Penal e em face da natureza dos crimes ambientais, provoca a doutrina clássica e consagra o ambiente natural como sujeito passivo da criminalidade, juntamente com a coletividade e a humanidade. ${ }^{42}$ Em síntese, o autor defende uma teoria antropocêntrica-ecocêntrica ou antropocêntricarelacional dos bens jurídicos ambientais, de acordo com a qual "o meio ambiente, mesmo sendo considerado um fim 'em si mesmo', deve ser alvo de proteção penal tendo em vista a idéia relacional de responsabilidade do homem não só para com a natureza, mas também para com as futuras gerações". ${ }^{43}$ A teoria defendida por SPORLEDER DE SOUZA sobre os bens jurídicos ambientais contrapõe-se às teorias: a) antropocêntrica, que não considera o ambiente como um "fim em si mesmo", entendendo que a sua proteção tem em vista a tutela de bens jurídicos estritamente antropocêntricos, sejam eles individuais ou supra-individuais; e b) ecocêntrica, inspirada no pensamento da deep ecology (ecologia profunda ou radical), que sustenta que o ambiente deve ser compreendido como um "fim em si mesmo", justificando-se a

\footnotetext{
${ }^{41}$ Recentemente, em 13.06.2007, foi proferida liminar (Proc. 2007.71.00.0198820/RS), pelo Juiz Federal Cândido Alfredo Silva Leal Junior, da Vara Ambiental da Justiça Federal de Porto Alegre, em favor de estudante de Biologia que se negava a participar das aulas práticas com o uso de animais. Na decisão, a Universidade do Estado do Rio Grande do Sul resultou obrigada a oferecer ao aluno aulas práticas alternativas àquelas com animais, nas disciplinas de Bioquímica II e Fisiologia Animal $\mathrm{B}$, de modo a evitar que o aluno viesse a ser reprovado pelo fato de exercer sua liberdade de consciência e convicção. A decisão (proferida pela primeira Instância) reconheceu o direito à objeção de consciência do aluno em face do uso de animais em aulas práticas, considerando a existência de métodos alternativos para o aprendizado. Tal análise ajusta-se ao comando constitucional imposto pelo princípio da proporcionalidade.

${ }^{42}$ SOUZA, Paulo Vinícius Sporleder de. "O meio ambiente (natural) como sujeito passivo dos crimes ambientais". Revista Brasileira de Ciências Criminais, Ano 12, n. 50, Set-Out, 2004. São Paulo: Revista dos Tribunais, pp. 57-90.

${ }^{43}$ SOUZA, "O meio ambiente...", p. 80.
} 
proteção penal independentemente de qualquer relação com o homem e com as suas necessidades, pois a natureza possui valores próprios que merecem ser tutelados de forma autônoma pelo Direito Penal. ${ }^{44}$

Na jurisprudência brasileira, a vedação de práticas cruéis contra a vida animal tem encontrado amparo no âmbito do Supremo Tribunal Federal, que decidiu, respectivamente, pela inconstitucionalidade da prática da "farra do boi" no Estado de Santa Catarina, bem como pela inconstitucionalidade da lei do Estado do Rio de Janeiro que regulamentava a "briga de galo" ", fundamentando ambas as decisões na previsão constitucional do art. 225, § I ${ }^{\circ}$, VII. Na decisão do STF relativamente à prática da "farra do boi" no Estado de Santa Catarina, o Ministro-Relator FRANCISCO REZEK, ao reconhecer que tal prática é abertamente violenta e cruel para com os animais, estando em desacordo com a Constituição, afirmou:

\footnotetext{
${ }^{44}$ SOUZA, “O meio ambiente...", pp. 78-80.

${ }^{45} \mathrm{Na}$ decisão, o STF analisou o caso à luz do princípio da proporcionalidade e ponderou o direito à manifestação cultural das comunidades catarinenses e a crueldade contra os animais inerente à "farra do boi”, vedando a referida prática e protegendo a integridade física e o bem-estar dos animais. "COSTUME. MANIFESTAÇÃO CULTURAL. ESTÍMULO. RAZOABILIDADE. PRESERVAÇÃO DA FAUNA E DA FLORA. ANIMAIS. CRUELDADE. A obrigação de o Estado garantir a todos o pleno exercício de direitos culturais, incentivando a valorização e a difusão das manifestações, não prescinde da observância da norma do inciso VII do artigo 225 da Constituição Federal, no que veda prática que acabe por submeter os animais à crueldade. Procedimento discrepante da norma constitucional denominado farra do boi" (STF, REXT 153.53 I8-SC, Rel. Min. Francisco Resek, decisão em 03.06.97).

46 “Constitucional. Meio Ambiente. Animais. Proteção. Crueldade. 'Briga de galos'. I A Lei 2.895, de 20.03.98, do Estado do Rio de Janeiro, ao autorizar e disciplinar a realização de competições entre 'galos combatentes', autoriza e disciplina a submissão desses animais a tratamento cruel, o que a Constituição Federal não permite: $\mathrm{CF}$, art. 225, §1 ${ }^{\circ}$, VII. II - Cautelar deferida, suspendendo-se a eficácia da Lei 2.895.03.98, do Estado do Rio de Janeiro". (STF, Pleno, ADI 1.856-6-RJ, Medida Liminar, Rel. Min. Carlos Veloso, decisão unânime, Diário da Justiça, Seção I, 22.09.2000, p. 69). Mais recentemente, em 14.06.2007, o Plenário do STF, sob a relatoria do Ministro Cezar Peluzo, declarou a inconstitucionalidade da Lei 7.380/98, do Estado do Rio Grande do Norte, que autorizava a criação, a exposição e as competições de aves das "raças combatentes", conhecidas como "brigas de galos" (ADI 3776-RN).
} 
"manifestações culturais são as práticas existentes em outras partes do país, que também envolvem bois submetidos à farra do público, mas de pano, de madeira, de "papier maché"; não seres vivos, dotados de sensibilidade e preservados pela Constituição da República contra esse gênero de comportamento.

Além das práticas referidas, é possível listar outras manifestações de crueldade contra animais, tais como a caça para fins meramente esportivos, touradas, brigas de cachorros, o que não afasta a discussão a respeito de eventual conflito com práticas arraigadas em determinadas comunidades e a sua possível superação. Ainda que não se esteja a sustentar uma equiparação com as práticas de crueldade com os animais acima referidas, merece destaque, no mínimo como uma questão a ser debatida, o exemplo trazido pela assim chamada cultura pet shop de "humanização" de animais domésticos (principalmente cachorros e gatos), aos quais é imposto o uso de utensílios e roupas ao modo de vestir humano, descaracterizando e desrespeitando a sua identidade animal (e natural). Da mesma forma que as práticas que infligem sofrimento aos animais, a violação da identidade natural dos animais é, a depender das circunstâncias, uma forma (possivelmente também cruel) de agredir a sua existência e a sua condição natural. Quando hoje se fala em "bem-estar animal", tal compreensão não passa pelo tratamento dos animais como se humanos fossem, mas sim pelo respeito à sua condição animal e identidade natural. Em outras palavras, a dignidade humana implica dever de respeito e consideração para com a vida não-humana e o reconhecimento de uma dignidade (valor intrínseco) das formas não-humanas de vida, visto que a dignidade da pessoa humana, embora tenha uma dimensão ecológica, não se confunde com a dignidade da vida, o que também deve ser sempre considerado na discussão sobre eventual embate entre direitos humanos e fundamentais e os interesses (ou direitos?) inerentes à vida não humana, aspecto que não poderá ser aqui aprofundado. 


\section{ALGUMAS QUESTÕES EM ABERTO - UM NOVO CONTRATO POLITICO- JURÍDICO SOCIOAMBIENTAL?}

A ampliação da noção de dignidade da pessoa humana (a partir do reconhecimento da sua necessária dimensão ecológica) e o reconhecimento de uma dignidade da vida não-humana apontam para uma releitura do clássico contrato social em direção a uma espécie de contrato socioambiental (ou ecológico), com o objetivo de contemplar um espaço para tais entes naturais no âmbito da comunidade estatal. Nesse sentido, MICHEL SERRES aponta a necessidade de se apostar, no contexto político-jurídico contemporâneo, na concepção de um contrato natural, onde o ser humano abandone a sua condição de dominador e "parasita" em face do mundo natural e assuma em face deste uma postura caracterizada pela reciprocidade na relação entre ser humano e ambiente, ou seja, aquilo que a Natureza dá ao homem é o que este deve dar a ela, tornando-a, de certo modo, sujeito de direito. ${ }^{47}$ Assim, da mesma forma como a Declaração dos Direitos do Homem buscou por fim ao parasitismo entre seres humanos, é chegado o momento histórico de, por meio de um contrato natural (ou melhor, socioambiental), se acabar, ou, pelo menos, minimizar, o impacto maléfico do parasitismo do Homem em relação à Natureza ${ }^{48}$. Há que ampliar o espectro de reconhecimento de sujeitos de direito no sentido de, contemplando novos parceiros de aventura natural, acrescentar ao contrato social a celebração de um contrato natural ou socioambiental de reciprocidade e interação entre os pactuantes. Assim como uma nova feição estatal se delineia, também um novo sujeito político deve emergir de tal conjuntura político-jurídica comprometida com o futuro. Propõese a reconciliação do homem natural com o homem político.

Por fim, registra-se a importância da conscientização e da sensibilização humana acerca do respeito à vida do animal não-humana

\footnotetext{
${ }^{47}$ SERRES, Michel. O contrato natural. Tradução de Serafim Ferreira. Lisboa: Instituto Piaget, 1990, p. 66.

${ }^{48}$ SERRES, O contrato natural, pp. 61-64.
} 
e dos entes naturais em geral. No diálogo travado entre os seus personagens Hans Castorp e Settembrini, THOMAS MANN ${ }^{49}$, em sua obra A montanha mágica, após referir que a essência do humanismo está vinculada ao respeito à dignidade da pessoa humana, destaca que $o$ "céu, por motivos de eqüidade, pertence aos pardais". Os valores fundamentais da nossa comunidade estatal (dignidade, liberdade, igualdade e solidariedade) devem, necessariamente, ser ampliados para além do espectro humano, no intuito de alcançarmos um patamar mais evoluído da cultura jurídica, da moral e do pensamento humano, o que, à luz das formulações levantadas, se revela também por meio do reconhecimento e conseqüente proteção e promoção da dignidade dos animais e da vida de um modo geral. Se tais questões, para além da evidente existência de deveres fundamentais também implicam o reconhecimento de direitos (subjetivos) fundamentais dos animais ou da natureza, ou se é preferível falar de interesses (objetivamente tutelados) fundamentais vinculados à vida não-humana ainda permanece em aberto. Da mesma forma, seguem carentes de amplo debate inúmeras outras questões, direta e indiretamente vinculadas ao tema ora versado. Relembre-se aqui que o que nos importa com o presente ensaio, é que sigamos logrando abrir e não cerrar portas e janelas por onde possam circular as idéias que movem a civilização e que seguem viabilizando que o Homem, ciente das suas limitações e de sua responsabilidade com a sua e as demais formas de vidas e com o meio no qual se inserem, encontre na dignidade da pessoa humana e na dignidade da vida um fundamento e um objetivo permanente, ético e jurídico, a respeitar e promover.

\footnotetext{
${ }^{49}$ MANN, Thomas. A montanha mágica. Tradução de Herbert Caro. Rio de Janeiro: Nova Fronteira, 2000, p. 217.
} 